\title{
Phantom contours: A new class of visual patterns that selectively activates the magnocellular pathway in man
}

\author{
V. S. RAMACHANDRAN and D. C. ROGERS-RAMACHANDRAN \\ University of California, San Diego, La Jolla, California
}

\begin{abstract}
The visual system of primates has two anatomical pathways: magno $(M)$ and parvo $(\mathrm{P})$. Here we report a novel technique for selectively stimulating the magnocellular pathway in man. The stimulus was a texture border between black spots and white spots displayed on a uniform gray field. This stimulus (Frame 1) was followed by Frame 2, in which all the black spots were replaced with white spots and all the white spots with black. The procedure was repeated in a continuous cycle; that is, spots reversed polarity without changing positions. At high temporal frequencies $(20 \mathrm{~Hz})$, subjects could not see the difference between the flickering spots, but could see a phantom contour separating the two indiscriminable regions. The difference between the spots themselves could be discriminated only at about $17 \mathrm{~Hz}$. Since the $\mathrm{M}$ pathway can follow high flicker rates but is insensitive to the sign of the border, we suggest that the phantom border is seen exclusively by the $M$ system. The P system, on the other hand, can report the sign of the border, but only at low flicker rates. Phantom contours provide a psychophysical scalpel for producing a temporary "lesion" in the parvocellular pathway of intact human subjects. One could therefore repeat all of classical psychophysics and physiology using phantom contours to determine whether or not a given visual process receives an $\mathbf{M}$ input. Also, these stimuli might provide a simple diagnostic test for revealing the loss of $\mathbf{M}$ cell function that occurs in early glaucoma.
\end{abstract}

The visual system in mammals, including primates, has two parallel anatomical subdivisions called the magnocellular and the parvocellular pathways (Figure 1). The two pathways originate in the retina, and their segregation is preserved all the way up to area 18 and beyond. Physiological experiments suggest that they differ in at least three important respects. First, the magno (M) cells in the LGN can follow very rapid changes in visual stimuli, whereas the response of the parvo (P) system is much more sluggish (Derrington \& Lennie, 1984; Wiesel \& Hubel, 1966). Second, $M$ cells respond well to a flashing black-white edge, but any given cell is completely indifferent to the sign of the edge. P cells, on the other hand, are sensitive to edge polarity; any given cell will respond to either black on white or white on black, but never to both. ${ }^{1}$ And lastly, another difference between the two systems involves color coding. $P$ cells respond well to both equiluminous chromatic borders (e.g., a red-green border) and luminance edges, and they are also sensitive to the sign of the border (for both types of stimuli). M cells, on the other hand, respond poorly to equiluminous chromatic borders, and even when they do respond they are indifferent to the sign

V.S.R. was supported by grants from the Air Force Office of Scientific Research (No. 89-0414) and the academic senate of the University of California. We thank Jennifer Luckrits for assistance with these experiments and Chandramani Ramachandran, John Allman, Pamela Sample, and Robert Weinreb for stimulating discussions. The authors' mailing address is Department of Psychology-0109, University of California, San Diego, La Jolla, CA 92093-0109. of the border. Indeed, they are sometimes described as being color-blind. On the basis of these findings, it is usually assumed that the $M$ system is concerned mainly with extracting edges, whereas a primary function of the $P$ system involves assigning surface colors to either side of the edge (Livingstone \& Hubel, 1987; Ramachandran, 1986.)

Since $M$ cells can follow rapid changes, one might expect them to be involved in motion perception, and there is some evidence that this is the case. The area 18 broad stripes project to area MT, in which the cells are sensitive to direction of motion but relatively insensitive to color (Zeki, 1978). The blob-thin-stripe cells, on the other hand, project to V4, in which the cells are sensitive to color but not to motion (Van Essen, 1979; Zeki, 1978).

Would it be possible to make any counterintuitive predictions about perception on the basis of this anatomical and physiological organization? An early attempt to directly test the perceptual consequences of this segregation was made by Ramachandran and Gregory (1978). On the basis of the information then available on the responses of LGN cells (De Monasterio, Gouras, \& Tolhurst, 1976; Dreher, Fukada, \& Rodeick, 1976; Gouras, 1968) and the work of Zeki (1978), they conjectured that human motion perception must be color-blind and performed two experiments. In their first experiment, they simply had a red line jumping left and right on a green background, and found that vivid apparent motion could still be seen even when the red and green were made equiluminous. The implication of this result, of course, is that color could indeed provide a cue for motion correspondence, and this 


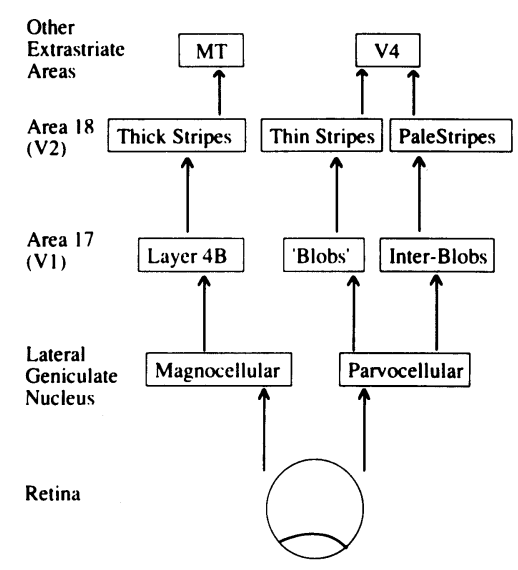

Figure 1. A simplified diagram of the visual pathways of primates (Ramachandran, 1991). Notice the three parallel "streams" that preserve their segregation all the way up to MT and V4. The parvocellular relay through layer $4 \mathrm{C}$ has been left out to make the diagram more comprehensible to psychologists. This composite diagram is based on information from many sources, including Livingstone and Hubel (1987), Zeki (1978), and Van Essen (1979).

seemed to contradict the physiology—at least as it was then known. In their second experiment, they used a randomdot kinematogram composed of red dots moving on a green background (instead of two isolated red lines), and found that the impression of an oscillating square disappeared completely, as predicted by the neuroanatomy. They concluded that there might be two motion systems, an early "front-end" system, which is relatively color-blind and is driven primarily by luminance, and a second, "form"based system, which is cue-invariant-that is, it can use many different types of contours, including chromatic borders and texture borders (Ramachandran, Rao, \& Vidyasagar, 1973). The latter system may correspond closely to what Braddick (1974) calls the "long-range" motion system, which is remarkably versatile in terms of the kinds of inputs it can use (e.g., see Ramachandran, 1988).

It has been suggested that visual functions that are reduced at equiluminance are also ones that are primarily processed by the $M$ pathway, and that equiluminous contours can therefore be used as a psychophysical "scalpel" for dissecting and studying different functional subsystems in the visual pathways (Livingstone \& Hubel, 1987; Ramachandran, 1990, 1991; Ramachandran \& Gregory, 1978). It should be emphasized, however, that the scalpel has proved to be rather blunt, perhaps due to the fact that although $\mathbf{M}$ cells are largely color-blind, a certain proportion of them do respond, to a limited extent, to equiluminous edges (Schiller \& Logothetis, 1990). This leakage of color borders into the $M$ system may explain why motion deteriorates at equiluminance but does not completely disappear (Cavanagh, Boeglin, \& Favreau, 1985; Ramachandran \& Gregory, 1978).

Would it be possible to design a stimulus that would selectively stimulate the $M$ pathway alone? Our attempt to create such a stimulus is depicted in Figure 2, in which a texture border is composed of black spots on the left and white spots on the right displayed on a homogeneous gray background of intermediate luminance (RogersRamachandran \& Ramachandran, 1991a, 1991b). We then replaced all the black spots with white and all the white spots with black, and repeated the sequence in a continuous cycle at about $20 \mathrm{~Hz}$. What you have then is two sets of spots flickering out of phase. But, surprisingly, what you see is a sort of paradoxical phantom border separating the two regions. If you compare any two spots in the display, they look identical-it is impossible to see whether they are flickering in phase or out of phase, yet the border defined by the two sets of spots is clearly visible! The reason for this might be that the border is seen exclusively by the $\mathbf{M}$ system (or by an $\mathbf{M}$-recipient area), which is insensitive to the sign of the border (whether white is to the left or the right of the edge) but can follow rapid rates of flicker. Indeed, since the only difference between the two sets of spots is temporal phase, and since the flicker rate $(20 \mathrm{~Hz})$ is too high for the $\mathrm{P}$ system to follow, we may conclude that the border ought to be visible only to the $M$ system.

The possibility of using phase-reversing edges to selectively stimulate the $M$ system was first suggested by Livingstone and Hubel (1987). The difference between their stimulus and the present one is that we have used a texture border composed of spots instead of a real luminance edge, and this has the advantage of getting rid of potential edge artifacts (e.g., Mach bands) that could arise from spatial nonlinearities. Also, since the spots that define the texture are themselves indiscriminable, our stimulus may be the only known example of a texture border defined by elements that look completely identical. And, finally, by studying temporal phase discrimination and examining the effects of contrast, dot density, blur, and so forth, we were able to establish clearly that

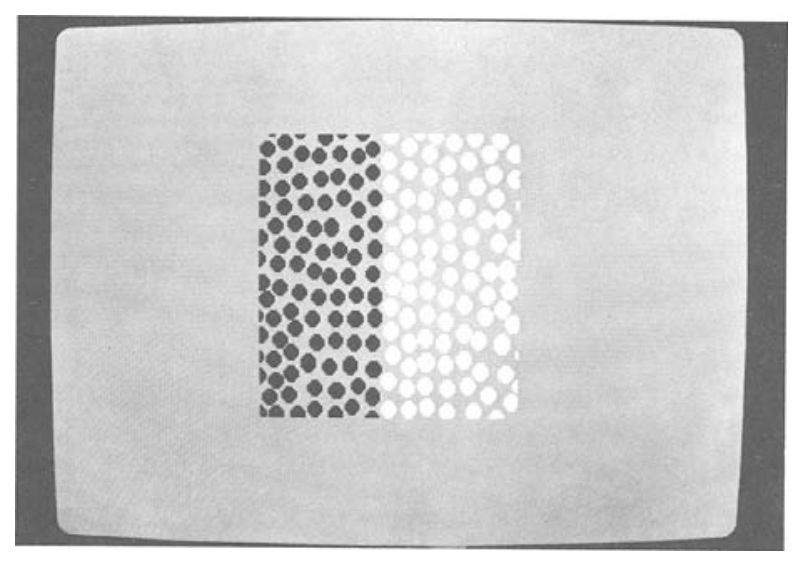

Figure 2. A single frame of a sequence used to generate phantom contours (Ramachandran, 1991). In the second frame, all the black spots are replaced with white spots (without changing their locations) and the black spots are replaced with white ones. If the two frames are presented in a continuous cycle at about $20 \mathrm{~Hz}$, the spots on the two sides of the border become indistinguishable but the border itself remains clearly visible. We have dubbed this border a phantom contour or magno contour. 
these contours do indeed selectively activate the M system, and this enabled us to determine the magnocellular contribution to a wide range of visual illusions.

One could repeat all of classical psychophysics using stimuli composed of phantom contours. Can such contours be used to generate a tilt aftereffect? Or how about the motion aftereffect, the barber-pole illusion, or the McCollough effect? It could be argued that using phantom contours is equivalent to making a reversible $\mathrm{P}$ lesion in the LGN in an intact human subject. Indeed, in a single (albeit very long) afternoon, one could repeat all traditional monkey lesion experiments without ever having to actually train monkeys or make lesions!

Our next step was to undertake a more formal experiment to demonstrate clearly that phantom contours could be seen even when the elements defining the contours were indiscriminable. Six naive subjects were run on 20 trials each. On each trial, 1 of 20 different letters, defined by phantom contours, was presented for $250 \mathrm{msec}$ (e.g., Figure 3). The entire stimulus subtended $13.4^{\circ}$ wide $X$ $15.4^{\circ} \mathrm{high}$ and was viewed from a distance of $0.4 \mathrm{~m}$. The spots themselves subtended $34^{\prime}$ of arc, and their luminances were $9 \mathrm{~cd} / \mathrm{m}^{2}$ (black spots) and $144 \mathrm{~cd} / \mathrm{m}^{2}$ (white spots). The luminance of the background gray was $92 \mathrm{~cd} / \mathrm{m}^{2}$. All stimuli were presented on a CRT using a Commodore Amiga microcomputer. Subjects correctly reported the letter on $91 \%$ of trials. But can we be sure that this discrimination is based on the contour itself and not on the elements that define it? To explore this, we used a display of just four spots that occupied the four corners of an imaginary square. The spots (38' of arc in diameter) were the same size as those used to construct the phantom contour stimuli. Each side of the square array subtended $2.4^{\circ}$. On any given trial, (1) the top two spots were out of phase with the bottom two spots, or (2) the left two spots were out of phase with the right two spots, or (3) two diagonally opposite corner spots were out of phase with the other two spots. The subject's task was to report which of these three stimuli he or she was seeing on any given trial. The stimulus duration was $1 \mathrm{sec}$. Six subjects were run on 20 trials each, and we found that their performance on this task was at chance level (mean $=40.8 / 120)$ even though the stimulus duration $(1 \mathrm{sec})$ was actually greater than in the previous experiment.

Next, we repeated the experiments using letters composed of red and green spots instead of black and white ones. The red and green spots were made equiluminous to each other (but not to the background), using the "minimally distinct" borders technique (Boynton, 1979). Six new subjects were used, and 20 letters defined by either black and white spots or red and green spots were presented in a random sequence ( 40 trials total), with each stimulus lasting $1 \mathrm{sec}$. Performance was correct for $94 \%$ of trials for the black-white letters but only $9 \%$ for the letters defined by colors, which supports our contention that the P system is essentially blind to the phantom borders. ${ }^{2}$

Using an additional 6 subjects, we measured the speed of alternation at which they could perform accurately on the 4-dot phase discrimination. The subjects adjusted flicker rate (five ascending and five descending trials). We found that the mean speed was $5.1 \mathrm{~Hz}$ for colored dots and $6.1 \mathrm{~Hz}$ for black white dots. The alphabetical letters, on the other hand, could be discriminated at arbitrarily high speeds (e.g., $30 \mathrm{~Hz}$ ) for the black-white spots but only at $5.6 \mathrm{~Hz}$ for the colored spots. Thus, the two thresholds-phase discrimination versus contour perception-are nearly identical for colored stimuli. These findings provide strong evidence for our view that phantom contours selectively stimulate the magnocellular pathway. ${ }^{3}$

We found that it was possible to make a "movie" consisting exclusively of phantom contours that move across the CRT even though the elements defining the contours were uncorrelated in successive frames. The impression of apparent motion was enhanced considerably if the whole display was blurred. One wonders whether motiondetecting cells in the middle temporal area (MT) (Allman, Miezin, \& McGuinnes, 1985) would also be capable of sensing moving phantom contours.

We also tried to determine whether binocular rivalry could be driven by phantom contours. We presented vertical phantom contours to the left eye and horizontal ones to the right eye, and found, to our surprise, that a plaid pattern was seen. When we reduced the alternation rate to about 7 or $8 \mathrm{~Hz}$, binocular rivalry was seen, suggesting that rivalry is driven mainly by contours that excite the $P$ pathway.

Next, we tried to convey the "tilt illusion" by using phantom contours, and found that the illusion remained undiminished. We may conclude, therefore, that the inhibition between orientation-selective cells that is thought to underlie this effect (Blakemore, Carpenter, \& Georgeson, 1970) must occur either within the magnocellular

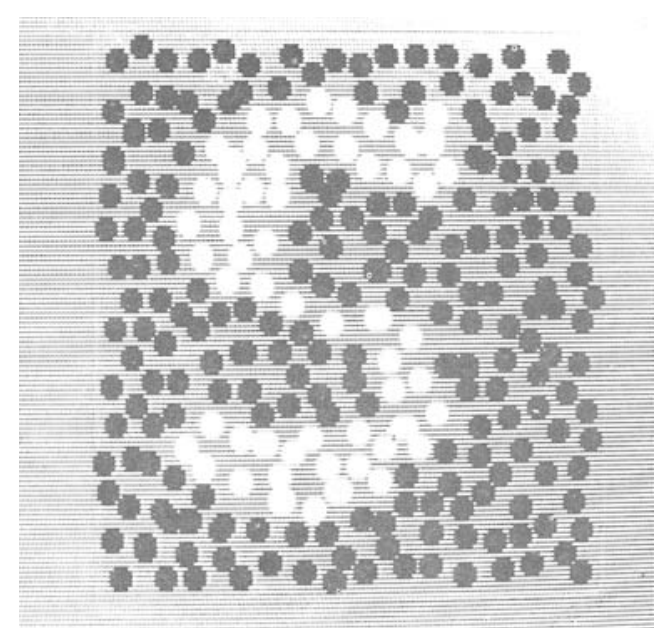

Figure 3. An example of an alphabetical letter portrayed by using phantom contours. This stimulus could be regarded as the equivalent of an Ishihara pseudoisochromatic test, except that it tests the competence of the magno pathways rather than the blob-thin-stripe system. Blurring the stimulus enhances the phantom contours. 
pathway itself (e.g., in the broad stripes in area 18) or higher upstream in the form areas of the temporal lobes.

Taken collectively, our findings lend some credibility to our view that phantom contours can be used as a psychophysical "scalpel" to isolate and study the functions of the $M$ system. In fact, they could be regarded as equivalent to Ishihara's pseudoisochromatic test plates, except that they test the integrity of the M pathway rather than chromatic pathways. There are at least three types of experiments in which phantom contours may be particularly useful. First, as we have seen, they can be used to determine psychophysically whether a given perceptual function (e.g., motion, orientation, etc.) can be mediated by the $\mathrm{M}$ pathway alone. Second, we believe that phantom contours can be used to probe for a host of physiological functions to determine whether or not single cells in any given visual area (e.g., MT or V4) receive an M contribution. And finally, they might provide a simple and noninvasive clinical test for revealing the selective loss of magnocellular function that occurs in early glaucoma (Quigley, Addicks, \& Green, 1982). In collaboration with P. Sample and $R$. Weinreb, we tested 2 patients recently and found that their ability to detect phantom contours was reduced considerably even though their acuity and spatial MTF (modulation transfer function) was normal.

\section{REFERENCES}

Allman, J., Miezin, F., \& McGuinness, E. L. (1985). Direction and velocity specific responses beyond the classical receptive field in the middle temporal area (MT). Perception, 14, 105-126.

Blakemore, C., Carpenter, R. H. S., \& Georgeson, M. A. (1970). Lateral inhibition between orientation detectors in the human visual system. Nature, 228, 37-39.

Boynton, R. M. (1979). Human color vision. New York: Holt, Rhinehart \& Winston.

BradDick, O. J.. (1974). A short range process in apparent motion. Vision Research, 26, 1751-1761.

Cavanagh, P., Boeglin, J., \& Favreau, O. E. (1985). Perception of motion in equiluminous kinematograms. Perception, 14, 151-162.

De Monasterio, F. M., Gouras, P., \& Tolhurst, D. J. (1976). Spatial summation, response pattern and conduction velocity of ganglion cells of the rhesus monkey retina. Vision Research, 16, 674-678.

Derrington, A. M., \& LeNNIE, P. (1984). Spatial and temporal contrast sensitivities of neurons in the lateral geniculate nucleus of macaque. Journal of Physiology (London), 357, 219-240.

Dreher, B., FUKADA, Y., \& RoDeICK, W. (1976). Identification classification and anatomical segregation of cells with $\mathrm{x}$-like and $\mathrm{y}$-like properties in the LGN of old-world primates. Journal of Physiology, 258, 433-452.

Gouras, P. L. (1968). Identification of cone mechanism in monkey ganglion cells. Journal of Physioloogy, London, 199, 533-547.

Livingstone, M., \& HuBel, D. H. (1987). Psychophysical evidence for separate channels for the perception of form, color, movement and depth. Journal of Neuroscience, 7, 3416-3468.

MerigaN, W. H., \& Eskin, T. A. (1986). Spatiotemporal vision of macaques with severe loss of $\mathrm{P}_{B}$ retinal ganglion cells. Vision Research, 26, 1751-1761.
Quigley, H. A., Addicks, E. M., \& Green, W. R. (1982). Optic nerve damage in human glaucoma. Archives of Ophthalmology, 100, 135-146.

Ramachandran, V. S. (1986). Visual perception: A biological theory. In S. Petry \& G. Meyer (Eds.), Illusory contours. Berlin: Springer-Verlag.

Ramachandran, V. S. (1988). Perception of depth from shading. Scientific American, 269, 76-83.

Ramachandran, V. S. (1990). Visual perception in people and machines. In A. Blake \& T. Troscianko (Eds.), Al and the eye. Briston: Wiley.

RamachandRan, V. S. (1991). 2-D or not 2-D-that is the question. In R. Gregory, J. Harris, \& P. Heard (Eds.), The artful brain. Oxford: Oxford University Press.

Ramachandran, V. S., \& Gregory, R. L. (1978). Does color provide an input to human motion perception. Nature, 275, 55-56.

Ramachandran, V. S., Rao, V. M., \& Vidyasagar, T. R. (1973). Apparent motion with subjective contours. Vision Research, 13, 1399-1401.

Rogers-Ramachandran, D., \& Ramachandran, V. S. (1991a). Phantom contours: A new class of stimuli that selectively activate the magnocellular pathway in man. Investigative Ophthalmology \& Visual Science (Supplement) 32, 1034.

Rogers-Ramachandran, D., \& Ramachandran, V. S. (1991b). Phantom contours: A new class of stimuli that selectively activate the magnocellular pathway in man. Society for Neurosciences Abstracts.

Schiller, P. H., \& Logothetis, N. K. (1990). The color opponent and broad band channels in the primate visual system. TINS, 13, 392-398.

VAN Essen, D. C. (1979). Visual cortial areas. In W. N. Cowan (Ed.), Annual Reviews of Neuroscience, 2, 227-263.

WiESEL, T. N., \& HUBEL, D. H. (1966). Spatial and chromatic interactions in the lateral geniculate body of the rhesus monkey. Journal of Neurophysiology. 29, 1115-1156.

ZEKI, S. M. (1978). Functional specialization in the visual cortex of the rhesus monkey. Nature, 274, 423-428.

\section{NOTES}

1. This statement is true for many cells in the P stream (e.g., the blobs) but not for all cells. Cells in the pale stripes are insensitive to sign (Livingstone \& Hubel, 1987). Further physiological experiments are needed to clarify this point.

2 . Is the inability to recognize letters conveyed by phase-alternating colored spots simply due to a reduction in contrast? We tested this hypothesis by lowering the contrast of our black-white letters. Even at contrast levels that were iower than the effective contrast of the colored stimuli, we found that the letters could be clearly discriminated. This is an important control, since the deterioration of certain visual processes at equiluminance is often cavalierly dismissed as being due to contrast reduction.

3. One problem with our interpretation is that some $P$ cells can follow very high temporal modulation (Merigan \& Eskin, 1986). It is conceivable, however, that the output of these cells is unavailable for the phantom-contour discrimination task. Also, even if the correlation with physiology is not exact, our results are interesting in their own right, since they demonstrate the existence of two systems-a "fast" achromatic system concerned with borders and a slow chromatic system that deals with surface colors.

(Manuscript received December 22, 1990.) 